\title{
Esquema de vacunación ideal vs Cartilla Nacional de Vacunación
}

\section{Ideal vaccination scheme against national vaccination card.}

Armando Reyes-Cadena

\section{INTRODUCCIÓN}

En México ha disminuido la morbilidad y mortalidad de las enfermedades prevenibles por vacunación, incluidas las de: poliomielitis, sarampión, difteria, tosferina, tétanos y tuberculosis meníngea; a lo anterior han contribuido particularmente las semanas nacionales de salud y otras estrategias que han permitido focalizar las acciones y cumplir con las metas nacionales e internacionales. ${ }^{1}$

Las dos intervenciones de salud pública que han tenido gran repercusión en la salud mundial son el agua limpia para consumo humano y la vacunación. Aun cuando se efectúa la vacunación, que es de las intervenciones de salud pública de mayor costo-efectividad e indiscutible costo-beneficio, en el mundo todavía mueren cada año dos millones de menores de edad por enfermedades prevenibles por vacunación. ${ }^{1}$

El programa de vacunación universal en México es una política pública de salud, cuyo objetivo es otorgar protección específica a la población contra enfermedades que son prevenibles a través de las vacunas. Este programa contiene las acciones que deben llevarse a cabo en todas las instituciones del Sistema Nacional de Salud del país para lograr el control, eliminación y erradicación de estas enfermedades. ${ }^{1}$

\footnotetext{
Médico adscrito a la consulta externa de Pediatría, Instituto Nacional de Pediatría, Ciudad de México.

Recibido: 3 de abril 2018

Aceptado: 11 de mayo 2018

Correspondencia Armando Reyes-Cadena cadenadr@yahoo.com.mx

Este artículo debe citarse como Reyes-Cadena A. Esquema de vacunación ideal vs Cartilla Nacional de Vacunación. Acta Pediatr Mex. 2018;39(4): 356-362.
} 
Los objetivos de la vacunación universal, en el marco de los compromisos nacionales e internacionales, son:

- Alcanzar y mantener $90 \%$ de vacunación con el esquema básico en menores de cinco años en cada entidad federativa.

- Mantener la erradicación de la poliomielitis por el polio virus silvestre.

- Prevenir brotes de poliomielitis por virus derivado de la vacuna.

- Mantener el control epidemiológico de la difteria.

- Mantener la eliminación del tétanos neonatal como problema de salud pública.

- Mantener el control epidemiológico del tétanos no neonatal.

- Mantener la eliminación del sarampión, rubéola y el síndrome de rubéola congénita.

- Mantener el control de la tosferina.

- Prevenir las formas graves de tuberculosis (meníngea y miliar).

- Prevenir infecciones invasivas por Haemophilus influenzae tipo b (meningitis, neumonía y artritis séptica) y por neumococo.

- Lograr el control epidemiológico de la parotiditis.

- Disminuir la severidad de la gastroenteritis causada por rotavirus.

- Prevenir las complicaciones de las infecciones respiratorias agudas por el virus de la influenza.

- Reducir la incidencia de infección por el virus del papiloma humano. ${ }^{1}$

México cuenta con una larga historia en la aplicación y producción de vacunas, con éxitos considerables. En 1978 se implementó, por decreto presidencial, la Cartilla Nacional de Vacunación, como un instrumento de registro y control de las dosis de vacunas que reciben los niños y niñas menores de cinco años. Su aplicación es obligatoria y su distribución gratuita en todas las instituciones del sector salud.

Cambios en el esquema básico de vacunación de México 1973-2013:

- 1973. El esquema protegía contra seis enfermedades: tuberculosis (BCG), poliomielitis (Sabin), difteria, tosferina y tétanos (DPT) y sarampión.

- 1997. Introducción del toxoide tetánico y diftérico $(\mathrm{Td})$.

- 1998. El esquema protegía contra ocho enfermedades al incorporarse la rubéola y parotiditis (vacuna SRP), en sustitución de la vacuna antisarampionosa monovalente $y$, para extender la protección a menores de 12 meses y 6 años de edad, con la intención de abatir la morbilidad por rubéola, meningitis o encefalitis por parotiditis y, de manera indirecta, el síndrome de rubéola congénita.

- 1999. El esquema protegía contra diez enfermedades al incorporarse hepatitis B y Haemophilus influenzae tipo b (vacuna pentavalente de células completas).

- 2004. El esquema protegía contra once enfermedades al incorporarse la influenza estacional.

- 2007. El esquema seguía protegiendo contra once enfermedades; en este año se cambió pentavalente de células completas por pentavalente acelular (Pertussis acelular y polio inactivada IPV) $\mathrm{DPaT}+\mathrm{Hib}+\mathrm{IPV}$.

- 2008. El esquema protegía contra 13 enfermedades al incorporarse la vacuna contra infecciones neumocócicas invasivas (PCV-7) y rotavirus. 
- 2011. El esquema seguía protegiendo contra 13 enfermedades, pero se cambió PCV-7 a PCV-13.

- 2012. El esquema protegía contra 14 enfermedades al universalizarse la aplicación de la vacuna contra el virus del papiloma humano y en las mujeres embarazadas se aplica al menos una dosis de Tdap.

- 2013. Se introdujo la aplicación de la vacuna de hepatitis $A$ a los niños de un año inscritos en estancias infantiles y guarderías del país.

- 2016. Se introdujo la vacuna Sabin bivalente (poliovirus tipos 1 y 3 ) que sustituye a la vacuna Sabin trivalente (poliovirus tipos 1,2 y 3$).{ }^{1}$

En la Figura 1 se muestra la Cartilla Nacional de Vacunación de México.

En la actualidad se considera que la Cartilla Nacional de Vacunación de México es una de las más completas de América Latina; sin embargo, aún falta incluir otros inmunógenos de importancia para tener una cartilla considerada ideal. En el rubro final de la Cartilla Nacional de Vacunación donde dice: "otras vacunas" los prestadores de servicios de salud debemos insistir a los pacientes en la imperiosa necesidad de aplicarlas.

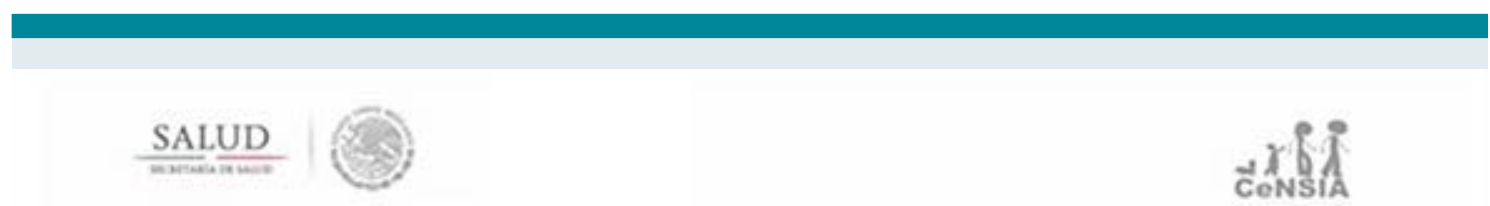

\section{Esquema Nacional de Vacunación para menores de 12 años}

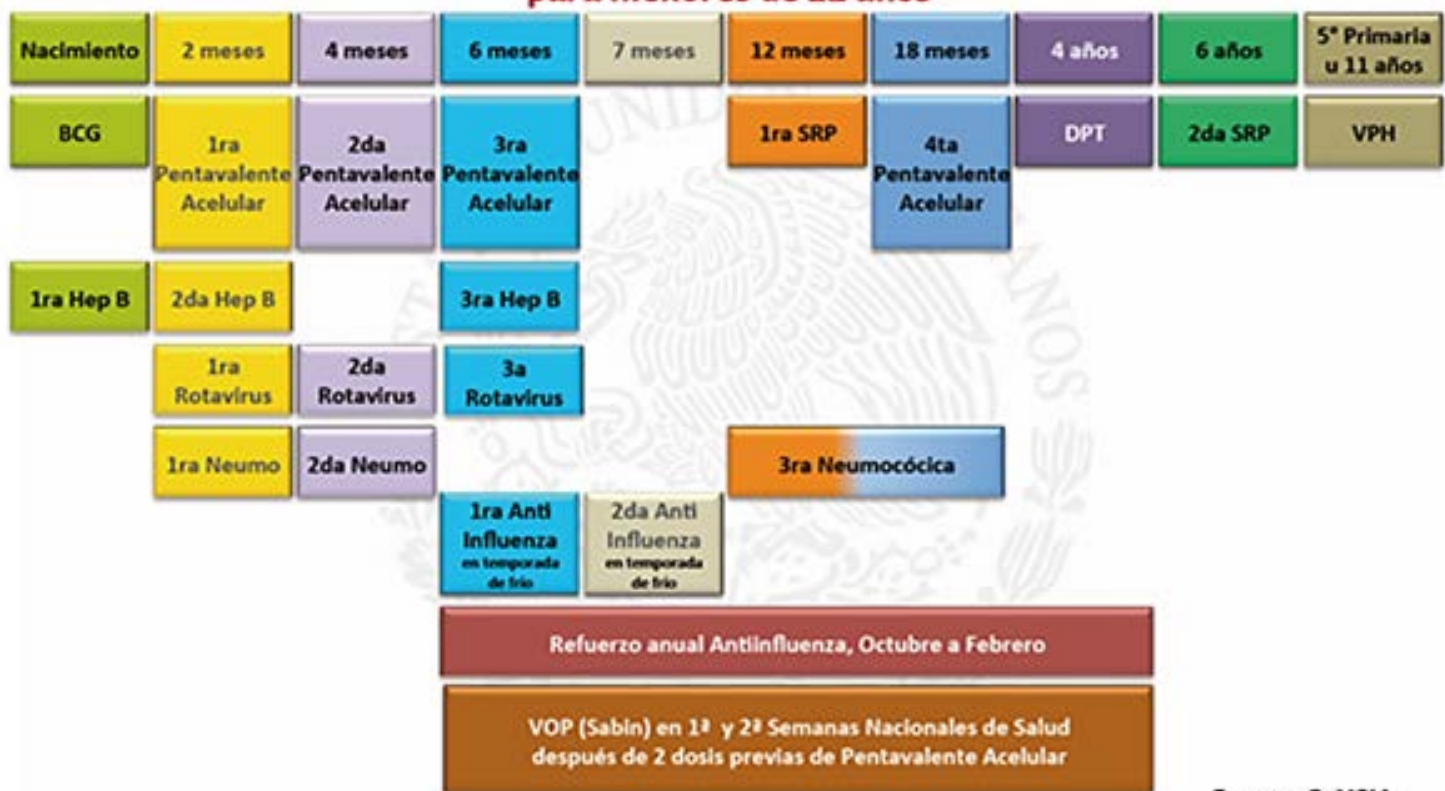

Fuente: CeNSIA

Figura 1. Cartilla Nacional de Vacunación. 
Para encarar los importantes retos que implica conseguir que estas nuevas vacunas se apliquen en los países donde se necesitan más y para aumentar el alcance y los resultados de los programas de inmunización, la comunidad sanitaria mundial en 2010 estableció la "Década de las vacunas", que tiene como objetivo que para el año 2020 las ventajas de la inmunización Ileguen a todas las personas, independientemente de dónde hayan nacido, quiénes sean o dónde vivan. Para hacer realidad esta visión, se elaboró el Plan de Acción Mundial de Vacunas, que fue aprobado por la Asamblea Mundial de la Salud. ${ }^{2}$

La decisión de introducir una nueva vacuna al programa nacional de inmunización implica muchos aspectos que deben considerarse al priorizar las inversiones en el sector salud. Diferentes factores podrían inducir a los países a considerar la adición de una vacuna a su programa nacional de inmunización. La vigilancia epidemiológica sistemática o los estudios de la carga de la enfermedad confirmada por laboratorio podrían revelar una alta incidencia o mortalidad debido a una enfermedad prevenible por vacunación. La enfermedad podría diseminarse en el país, incrementar su incidencia o volver a emerger. Una vacuna nueva o mejorada que haya llegado al mercado o una nueva recomendación de la Organización Mundial de la Salud también podría incentivar a los países a considerar la introducción de una nueva vacuna en su programa. $^{2}$

Todos los países necesitan establecer prioridades para determinar qué problemas de salud deben abordar y qué intervenciones específicas deben implementar, de acuerdo con los problemas de salud y las limitaciones de recursos que enfrentan, sobre todo los países en desarrollo. Las preguntas que pueden plantearse para establecer las prioridades de la enfermedad y la vacuna son:

1. ¿Es la enfermedad una causa significativa de carga de morbilidad?
2. ¿La prevención de la enfermedad contribuye de forma significativa a los objetivos y se alínea con las prioridades establecidas en los planes nacionales de salud y desarrollo?

3. ¿La enfermedad es percibida como importante por el público y la comunidad médica?

4. ¿La vacuna es recomendada por la OMS y el control de esa enfermedad está alineado con las prioridades mundiales o regionales?

5. ¿La prevención de la enfermedad contribuye a mejorar la equidad entre las clases socioeconómicas y los grupos de población?²

Con base en lo anterior debe considerarse integrar a la Cartilla Nacional de Vacunación de México las siguientes vacunas:

\section{Varicela}

Es la enfermedad exantemática más frecuente en niños. En México se reportaron, hasta la semana epidemiológica 52 (del 24 al 30 diciembre de 2017) un total de casos acumulados de varicela de 148,836 . En cuanto a la edad, el grupo con mayor afectación es el de menores de 10 años. El comportamiento de la varicela en nuestro país es cíclico, cada cuatro o cinco años habrá aumento en su incidencia. ${ }^{3}$

Aunque no suele considerársele un problema prioritario de salud pública, las consecuencias y el efecto socioeconómico de esta enfermedad, que afecta prácticamente a todos los niños y que es motivo de ausentismo escolar y laboral (de los encargados del cuidado del enfermo), no deben subestimarse. Es causa frecuente de consulta médica y hospitalización $y$, en caso de afectar a personas pertenecientes a los grupos de alto riesgo (adultos, embarazadas, pacientes inmunodeprimidos), genera 
mayor morbilidad y mortalidad, las complicaciones más frecuentes son sobreinfección bacteriana de las lesiones de la piel por Staphylococcus o Streptococcus, lo que puede llevar a formación de abscesos, fascitis necrotizante o choque tóxico, neumonía, encefalitis, ataxia cerebelosa aguda, trombocitopenia, varicela hemorrágica, que pueden dejar secuelas persistentes o provocar la muerte. En relación con la edad, las complicaciones son más frecuentes en menores de un año y en mayores de 15 años. ${ }^{4}$

La OMS recomienda evaluar la posibilidad de incorporar la vacuna contra la varicela a los programas nacionales de vacunación, teniendo en cuenta la epidemiología local de la enfermedad y sus repercusiones socioeconómicas en las que se basará la decisión de considerarla una medida prioritaria de salud pública. Asimismo, sugiere considerar la inmunización infantil sistemática contra varicela en los países en los que la vacuna sea asequible y en los que se pueda alcanzar una cobertura elevada y sostenida de vacunación $(85-90 \%){ }^{5}$

Con base en estimaciones conservadoras de la OMS, la carga de enfermedad mundial y anual por varicela incluiría 4,200,000 complicaciones graves con requerimiento de hospitalización y 4200 muertes. $^{5}$

Los datos obtenidos en la etapa prevacunación, en países industrializados que actualmente vacunan de manera sistemática, mostraban tasas de mortalidad por esta enfermedad de alrededor de 3 casos por cada 100,000 habitantes. ${ }^{5}$

Estos datos, en conjunto con los resultados positivos obtenidos de numerosos análisis de seguridad, eficacia y costo-efectividad de la vacuna de la cepa atenuada Oka, han justificado la introducción de este biológico a los programas de inmunización infantil de varios países industrializados. $^{5}$
Varios estudios han demostrado que la vacunación sistemática contra varicela a niños constituye una medida costo-efectiva o costoahorrativa (la intervención es más efectiva y menos costosa que la no intervención). Un análisis de costo-beneficio efectuado en Estados Unidos puso de manifiesto que la vacunación sistemática a niños podría permitir un ahorro de hasta cinco veces la inversión efectuada en la vacunación. Incluso al considerar solo los costos directos, los beneficios serían prácticamente iguales a ellos. No hay estudios similares llevados a cabo en países en vías de industrialización. ${ }^{5}$

De acuerdo con la experiencia japonesa, la inmunidad contra la varicela tras la vacunación dura por lo menos 10-20 años. En Estados Unidos, la vacunación infantil contra la varicela confiere protección de 70-90\% contra la infección y más de $95 \%$ contra la enfermedad grave hasta 7-10 años después de la inmunización. ${ }^{5}$

La introducción de esta vacuna al calendario nacional de vacunación en forma universal, gratuita y obligatoria, está basada en el principio de equidad en salud, porque la enfermedad afecta a todos los niños, independientemente de su condición social. ${ }^{5}$

\section{Hepatitis A}

La infección por virus hepatitis A coexiste en todo el mundo y causa la forma aguda de la enfermedad, sobre todo en los niños. En general, la recuperación es prolongada y la gravedad se relaciona con la edad. ${ }^{6}$

Diversos estudios han demostrado que $90 \%$ de los mexicanos tienen concentraciones importantes de anticuerpos IgG contra el virus de la hepatitis A y que éstos se adquieren en la edad preescolar, en particular en las clases socioeconómicas bajas. ${ }^{6}$ 
En el caso de la hepatitis A 10 a 15\% de los casos pueden prolongarse hasta seis meses, ser fulminante y ocasionar insuficiencia hepática y muerte.

En México, las hepatitis virales (incluida la hepatitis A) son un grave problema de salud pública, por lo que deben reforzarse las medidas de prevención y control pertinentes con lo que sería posible disminuir la morbilidad y mortalidad por hepatitis, ${ }^{6}$ por lo anterior deberá considerarse integrar la vacuna de la hepatitis $\mathrm{A}$ al cuadro básico de vacunación.

\section{Meningococo}

La enfermedad meningocócica invasiva causada por Neisseria meningitidis es uno de los padecimientos más graves, debido a su rápida progresión que puede conducir al paciente a la muerte en horas. Tiene alto impacto en la salud pública; en el mundo se reportan 500,000 casos anuales con mortalidad de $10 \%$, aunque en brotes y epidemias la tasa de mortalidad puede incrementarse a $30 \%{ }^{7}$

La mayoría de los casos de enfermedad meningocócica son esporádicos, con variaciones estacionales y brotes que ocurren a intervalos irregulares. $^{7}$

En América Latina la incidencia de la enfermedad es muy variable y es quizá subestimada, esto por la dificultad de recuperar el microorganismo por la limitación de obtener muestras adecuadas para cultivo y por la administración previa de antibióticos. $^{7}$

La incidencia en México es de 0.6 por cada 100,000 casos; se reportan los serogrupos Y, C, B y W. El más frecuente es el serogrupo C. En México oficialmente se reportan alrededor de 80 casos anuales confirmados.
Se ha observado que en México los grupos de edad más afectados son los menores de un año, seguidos del grupo de 1-4 años y el de 45-49 años, por lo que deben considerarse grupos blanco para fines de vacunación. ${ }^{8}$

El estado de portador en la población mexicana se estima en $2.97 \%$ para la población en general.

Si bien en México la enfermedad meningocócica no se considera un problema de salud pública porque tiene una tasa de incidencia anual de 0.06 casos por 100,000 habitantes, se cataloga de bajo riesgo de incidencia (menos de 0.5 por 100,000 habitantes), por su alta tasa de mortalidad y el hecho de que hasta $20 \%$ de los supervivientes a la enfermedad meningocócica padecen secuelas a largo plazo, como sordera, déficit neurológico o amputaciones de extremidades y al considerar que la vacunación es la mejor estrategia de control para prevenir la enfermedad meningocócica, deberá contemplarse su integración al esquema nacional de vacunación. ${ }^{9}$

Desde el inicio del Programa Nacional de Inmunizaciones en México se ha modificado el esquema básico de vacunación; durante este periodo, el número de inmunógenos pasó de 6 a 14, por lo que representa uno de los esquemas más completos en América Latina.

\section{REFERENCIAS}

1. Programa de Acción Específico. Vacunación Universal 2013-2018. Programa Sectorial de Salud. Primera edición. México; 2014.p. 11-33.

2. Principios y consideraciones para agregar una vacuna en el programa nacional de inmunización. De la decisión a la implementación y el monitoreo. Organización Mundial de la Salud. Abril 2014;2-18.

3. Cabrera-Gaytán D, Muñoz-Mendoza W, Gómez-Altamirano C. Comportamiento epidemiológico de la varicela en México: 18 años de estudios y estimaciones para los próximos cinco años. Revista de Enfermedades Infecciosas en Pediatría. 2009; XXII(87):77-82.

4. Centro Nacional para la Salud de la Infancia y la Adolescencia. Secretaría de Salud. Manual de Vacunación. México; 2017;13-209. 
5. Ministerio de Salud de la República de Argentina. Lineamientos Técnicos. Fundamentos de la Introducción de la Vacuna contra Varicela. 2015:6-15.

6. Murguía-Martínez P, Kuri-Morales P. Panorama epidemiológico de las hepatitis virales en México. Gac Méd Méx. 2007;133(5):487-492.

7. Hernández-Porras M, González-Saldaña N. Vacunas: Enfermedad meningocócica. Revista de Enfermedades Infecciosas en Pediatría 2013;XXVII(106):389-393.
8. Camacho-Amor M. Boletín Epidemiológico. Sistema Nacional de Vigilancia Epidemiológica Sistema único de Información. Perfil Epidemiológico en México de Meningitis Meningocócica (primera parte). 2013;30(13):1-5.

9. Palazzi-Sáfadi M, Leite-Cintra O. Epidemiology of meningococcal disease in Latin America: current situation and opportunities for prevention. Neurological Research. 2010;32(3):263-270.

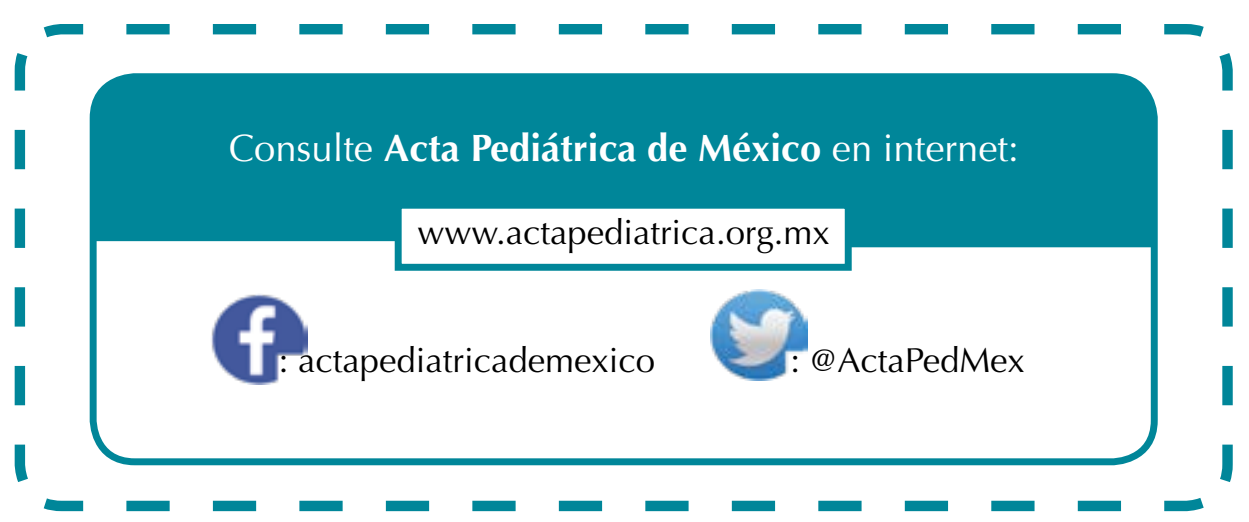

